\title{
PERNICIOUS ANAEMIA
}

\author{
K. B. TAYlOR, D.M., M.A., M.R.C.P. \\ Medical Research Council Gastroenterology Research Unit, The Radcliffe Infirmary, Oxford
}

\begin{abstract}
DEFICIENCY of vitamin $B_{12}$ (cyanocobalamin) in man results in a macrocytic anæmia, leucopænia, the appearance of megaloblasts and giant band cells in the marrow, reduced formation of platelets, and also changes in the peripheral and central nervous systems. In temperate climates the most common cause of vitamin $\mathrm{B}_{12}$ deficiency is pernicious anæmia. This is by no means a rare disease, having an incidence in Great Britain of 1.27 per 1,000 (Scott, 1960). For nearly a century it has been recognized that the anæmia is associated with a degenerate gastric mucosa (Fenwick, 1870); yet the causes of such gastric degeneration are still obscure.
\end{abstract}

\section{Absorption of Vitamin $B_{12}$}

It is firmly established that the atrophic gastric mucosa found in pernicious anæmia does not secrete adequate amounts of Castle's intrinsic factor. Defective absorption of vitamin $B_{12}$ in the small gut results. The bulk of evidence suggests that in man the stomach is the only important site of production of intrinsic factor. Recent claims that intrinsic factor does not exist and that proteolysis can release the vitamin $B_{12}$ from food as a complex capable of being absorbed without intrinsic factor (Heathcote and Mooney, 1958) have still to be substantiated. A great weight of experimental evidence using labelled vitamin $\mathbf{B}_{12}$ firmly establishes the fact that in man and in the rat removal of the secretory gastric mucosa results in a failure of absorption of small doses of free cyanocobalamin and that the addition of material prepared from gastric juice or gastric mucosa restores normal absorption. The intrinsic factor activity in such preparations is independent of proteolytic activity.

It is important to stress here that in discussions of absorption of vitamin $B_{12}$ the type of absorption referred to is that which can best be termed physiological, since it is the predominant type in normal conditions. The mechanisms responsible for it can mediate the absorption of not more than about $5.0 \mu \mathrm{g}$. cyanocobalamin given as a single dose in a normal subject (Abels, 1959). This maximum has been accounted for by postulating blocking of intestinal acceptors (Glass, Boyd and
Stephanson, 1954) and there is reason to believe $\vec{\circ}$ that such blocking is very transient and has ceased to influence further absorption of the $\vec{\omega}$ vitamin before absorbed vitamin $\mathrm{B}_{12}$ has passed beyond the intestinal wall (Reynell, Spray and Taylor, 1957).

If vitamin $\dot{B}_{12}$ is given by mouth in sufficiently large doses to patients with pernicious anæmia or $\dot{\omega}$ after total gastrectomy, a rise in concentration of $O$ vitamin $B_{12}$ activity in the plasma (Ross, Mollin, Cox and Ungley, I954), or, when labelled material is used, the appearance of radioactivity in the plasma (Doscherholmen and Hagen, 1957a), provide evidence of absorption in the absence of intrinsic factor. There is no reason to suppose $\frac{c}{\omega}$

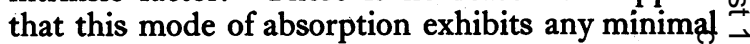
threshold effect, other than one possibly imposeg by 'binding' of the vitamin by the contents of. the stomach and small gut. It probably operates at any level of concentration of vitamin $B_{12}$ in the gut but, at low concentrations in the normal subject, it is overshadowed by the absorption mediated by intrinsic factor.

The case for the existence of intrinsic factor is $\overrightarrow{\vec{A}}$ strengthened by studies in children and youths $\frac{0}{3}$ with so-called juvenile pernicious anæmia (Lambert, Prankerd and Smellie, r96r), in whom the secretion of acid and pepsinogen is unimpaired, the gastric mucosa may appear normal and absorption of vitamin $B_{12}$ is defective but is restored by the administration of gastric juice from a normal person.

The absorption of vitamin $B_{12}$ as it occurs naturally in animal protein has not been studied, $ᄋ$ apart from some experiments with labelled $D$ vitamin $B_{12}$ in liver (Reizenstein and Nyberg, 1959), which have suggested that the vitamin $N$ incorporated in liver may be better absorbed than pure cyanocobalamin.

Recently a 'vitamin $B_{12}$ coenzyme' has been $N$ studied (Weissbach, Toohey and Barker, 1959), which may represent a naturally occurring formo of vitamin $B_{12}$, but it has yet to be established $\Phi$ whether it is better absorbed from the gastro- ? intestinal tract than is cyanocobalamin (Wasser- $\frac{T}{0}$ man, Estren, Brody and Herbert, 1960).

Proteolysis may be an important initial factor 
in releasing :vitamin $\mathrm{B}_{12}$ from bound, undialysable forms in food (Cooper and Castle, 1960). It seems unlikely that gastric proteolysis is necessary to release this bound vitamin $B_{12}$, since in some patients with atrophic gastritis, production of acid and pepsin is absent, yet they are not deficient in vitamin $B_{12}$.

This matter is further complicated by the observation that a test dose of labelled cyanocobalamin is better absorbed (that is to say, a greater percentage of the dose is absorbed) when it is given in a meal than by itself (Deller, Germar and Witts, 196r). This phenomenon may be due to stimulation of gastric secretion of intrinsic factor by food, but it seems more likely to be due to the more prolonged presentation of the test dose of the vitamin to the small intestinal mucosa when it is dispersed in a meal.

The site of absorption of vitamin $B_{12}$ in physiological concentrations is limited to the small intestine. Experiments with rats suggest that , the middle segments absorb most of the vitamin (Booth, Chanarin, Anderson and Mollin, 1957; Reynell, Spray and Taylor, 1957), whereas in the human the distal ileum shows maximal uptake (Booth and Mollin, 1959). The reason for this species difference is not clear. With high concentrations probably any mucosal surface will absorb some of the vitamin.

Absorption beyond the mucosa is effected by the portal blood stream and not by the intestinal lymphatics (Taylor and French, 1960).

The way in which intrinsic factor facilitates absorption of vitamin $B_{12}$ is not known. This problem is intimately related to the equally unsolved problem of the nature and identity of intrinsic factor. No material with intrinsic-factor activity which would satisfy a chemist's criteria of purity has been isolated. Intrinsic-factor activity may prove to be due to a number of active groupings arranged in either a specific or non-specific way on the surface of identical, similar or even dissimilar large molecules. These large ' carrier' molecules might play a similar role for other active groups. Thus it may prove to be possible to extract in a reproducible manner material of constant activity which can never be considered pure. There is little evidence to suggest that this has yet been accomplished, though recent work has produced material demonstrably active in doses of tens of micrograms (Heatley, Sheikh and Taylor, 1960; Bromer and Davisson, 1961).

- Much argument exists as to whether an essential property of material possessing intrinsic-factor activity is its capacity to 'bind' vitamin $B_{12}$, as measured by dialysis in membranes or by microbiological assay. For the reasons referred to in the previous paragraph and the well-established fact that vitamin $\mathrm{B}_{12}$-binding persists in material in which intrinsic-factor activity has been destroyed (Spray, 1952; Taylor, Mallet and Spray, 1958), there is no answer to this problem. Demonstrations that vitamin $B_{12}$ bound to material possessing : intrinsic-factor activity is absorbed preferentially to unbound vitamin and that excess of such intrinsic-factor preparations may exert a markedly inhibitory effect on the absorption of vitamin $B_{12}$ has led to the concept that excess intrinsic factor competes for a limited number of intestinal receptor sites in a way illustrated schematically in Fig. I (Taylor, Mallett, Witts and Taylor, I958). Whether such a scheme represents the true state of affairs remains to be tested when purer preparations of intrinsic factor become available.

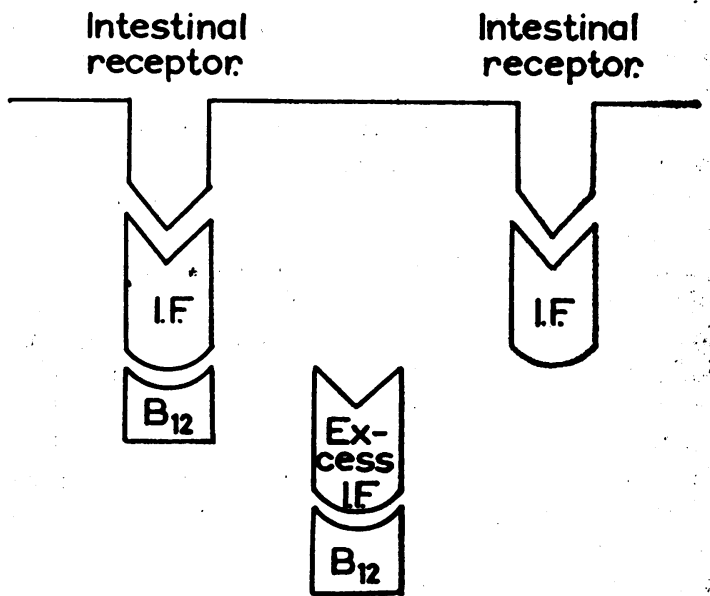

FIG. 1.-A schematic representation of the possible mechanism underlying observed inhibition of absorption of vitamin $B_{12}$ in the presence of excess intrinsic factor.

\section{Metabolic Functions of Vitamin $B_{12}$}

Although the structure of vitamin $B_{12}$ and that of many of its analogues are known, its actions in the metabolic pathways of tissues of higher mammals have not been established. In lower mammals and in fowls decreased rate of growth is the only constant expression of deficiency and no changes in the blood or nervous system occur, except that a macrocytic anæmia has been produced in the guinea-pig (Slungaard and Higgins, 1956). Such species differences are unexplained.

The widespread distribution of the vitamin in tissues suggests that it has general metabolic functions. The state in which it exists in tissues is not known, though it is unlikely to be as cyanocobalamin. Recently a vitamin $\mathrm{B}_{12}$-containing coenzyme has been obtained from rabbit 
liver and from Propionobacteria (Weissbach, Toohey and Barker, 1959), for which is claimed anti-pernicious anæmia activity, but this has not been firmly established. In vitro the complex is active in the conversion of propionate to succinate in cell-free extracts of Propionobacteria, a reaction requiring biotin and coenzyme $A$. (Stadtman, Overath, Eggerer and Lynen, 1960).

The dibenziminazole group is essential for biological activity in more selective organisms like Ochromonas. The low biological activity of the analogues of vitamin $B_{12}$ in which the dibenziminazole is replaced by a purine ring may be due to the inability of such compounds to link effectively with specific proteins in cellular systems.

There is good evidence that vitamin $B_{12}$ is involved in transmethylation reactions in lower organisms. Johnson and his colleagues (Johnson, 1955) obtained some indication in vitamin $\mathrm{B}_{12^{-}}$ deficient piglets that transmethylation from methionine was not impaired, whereas methyl transfer from glycine was.

Hæmatological remission induced with folic acid in pernicious anæmia suggests a relationship between vitamin $\mathrm{B}_{12}$ and folic acid, and it was thought that the interrelationship occurred in pathways of nucleic acid synthesis, which are disordered in vitamin $B_{12}$ deficiency. Folic acid is converted to folinic acid which was thought to influence purine and pyrimidine synthesis with vitamin $B_{12}$ operating in some way in the interconversion to nucleosides. However, thymidine is now known not to produce remissions in pernicious anæmia, contrary to earlier reports, though thymidine and other desoxyribosides can replace vitamin $B_{12}$ in cultures of lactobacilli.

Smith (1958) has put forward the hypothesis that vitamin $B_{12}$ is intimately related to protein synthesis and that diversity of expression of deficiency is due to failure of synthesis of many enzymes. No better theory has been advanced. The megaloblastosis, the neurological lesions and the increased random destruction of circulating erythrocytes and evidence of 'ineffective' erythropoiesis in pernicious anæmia still remain to be explained.

\section{The Clinical Picture of Pernicious Anzemia}

The foregoing sections are preliminary to the main topic of pernicious anæmia, its diagnosis and treatment.

The underlying cause, which may be a serious one, of any anæmia should be looked for. In pernicious anæmia the increased risk of subsequent development of gastric carcinoma constitutes an additional reason for making a correct diagnosis and for continued observation of the patient.
The alternative to proper diagnosis and effective therapy in pernicious anæmia is the use of $z$ polyhæmatinics developed by some drug firms $\stackrel{\AA}{\complement}$ for the 'shot-yun' therapy of anæmia. These $C$ preparations contain either iron, small amounts $\overrightarrow{\vec{s}}$ of vitamin $B_{12}$ and folic acid, with some other $\frac{\sigma}{\sigma}$ water-soluble vitamins, or the same factors plus semi-purified hog intrinsic factor. The first group $\overline{\bar{c}}$ of drugs is dangerous in initial treatment and $\vec{\Phi}$ maintenance therapy of pernicious anæmia, be- 2 cause their content of vitamin $B_{12}$ is too small to के permit the absorption of an effective amount, and $\overrightarrow{0}$ the folic acid they provide may correct the $\overrightarrow{-}$ anæmia but further deplete the body stores of $\vec{\omega}$ vitamin $B_{12}$ and precipitate or aggravate lesions of $\frac{}{0}$ the central nervous system (Ross, Belding and $\frac{0}{3}$ Paegel, 1948). The dose of folic acid which, together with dietary folic acid, is capable of producing a hæmatological response may be as little as $0.4 \mathrm{mg}$. daily (Fig. 2).

Preparations containing intrinsic factor may be $\stackrel{\circ}{\circ}$ less harmful but, should resistance to heterologous intrinsic factor develop (Schwartz, Lous and Meulengracht, 1957) the same dangers may obtain with their prolonged use.

\section{Diagnosis of Pernicious Ansemia}

Davidson (1957) has given a comprehensive account of the clinical findings in this disease. none of which is pathognomonic. The most freg quently occurring symptoms of pernicious anæmia are tiredness and lassitude, soreness of the tongue and paræsthesiæ. Anorexia, loss of weight and diarrhœa or constipation are inconstant features. Fever occurs in about $20 \%$ of all untreated patients. The classical signs of grey hair, blue eyes and a lemon-yellow tint to the skin are well known but not of decisive value. Occasionally the facial appearance of the female patient is strikingly like that seen in myxœdema. Perhaps the most valuable pointer to diagnosis is to be found in the association of clinical anæmia, a pale smooth tongue and mild symmetrical peripheral sensory impairment, in a patient over the age of 40. Unmistakable icterus, a palpable spleen and evidence of damage to the spinal tracts are $\frac{D}{O}$ nowadays so uncommon as to raise the possibility of more serious underlying disease when $\mathcal{N}$ such signs are present. A minor degree of mental blunting is not uncommon, though its detection $\mathrm{N}_{\mathrm{N}}$ is often postponed until the patient has been $\mathrm{W}$ properly treated. More serious mental disturbance may occur and many instances are on record of $\stackrel{\varrho}{C}$ patients being rescued from mental institutions $\mathbb{D}$ and restored to a normal mental state with injections of vitamin $B_{12}$.

Examination of the peripheral blood will reveal a macrocytic anæmia and hypersegmentation of 


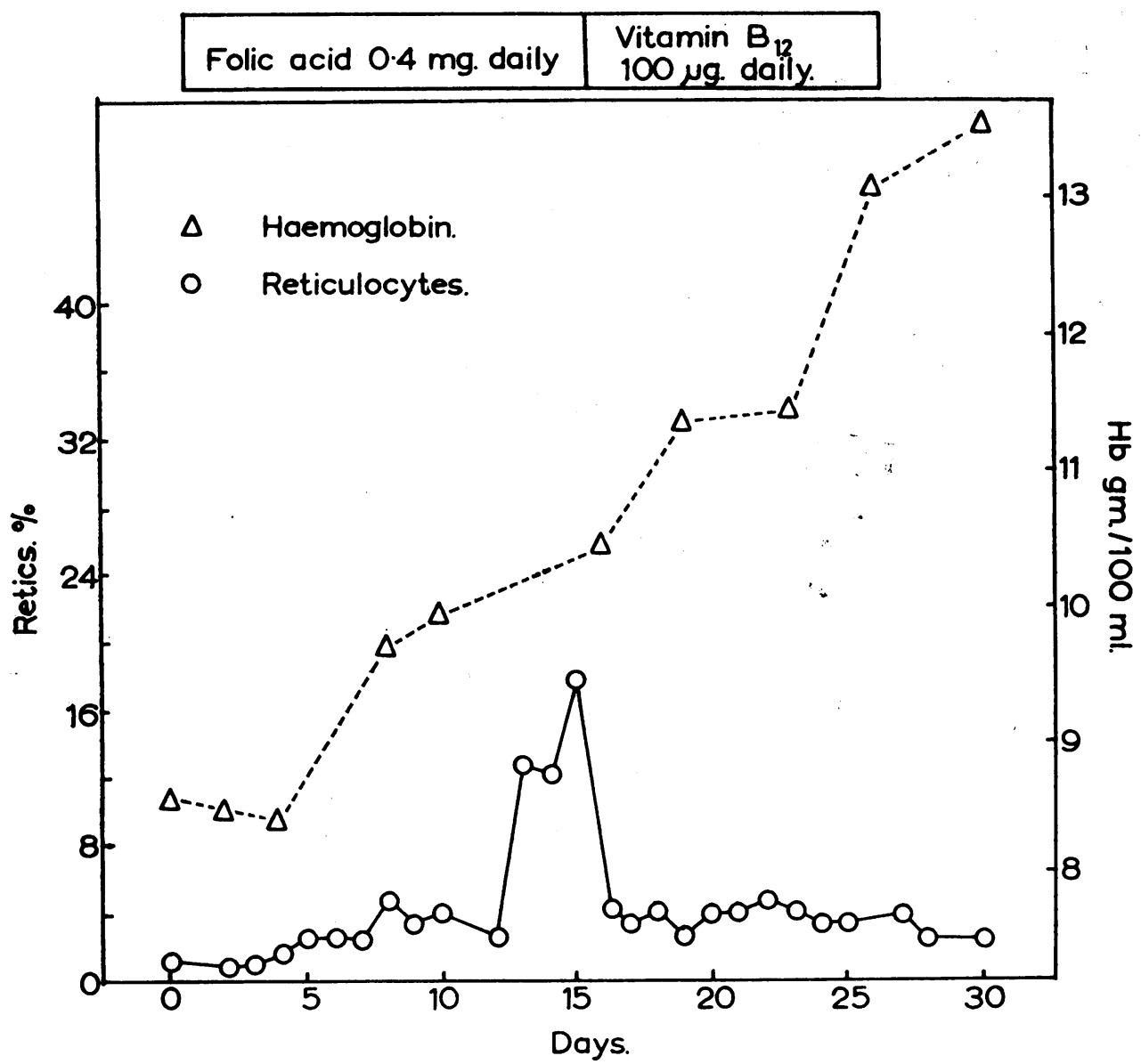

FIG. 2.-Hæmatological response of a patient with pernicious anæmia to a daily dose of $0.4 \mathrm{mg}$. folic acid.

the polymorphonuclear leucocytes. These findings indicate strongly a diagnosis of deficiency of vitamin $B_{12}$ or of folic acid or of both, but minor degrees of change in the peripheral blood may pass unrecognized and examination of the sternal marrow for megaloblastosis establishes the diagnosis more firmly.

The separation of pernicious anæmia from some form of small intestinal malabsorption syndrome is usually successful without further elaborate tests. A case can be made for performing all the commoner tests of the state and activity of the gastric mucosa, such as: acid secretion; pepsin production; plasma pepsinogen concentration or uropepsinogen excretion; intrinsic-factor activity of the gastric juice; gastric biopsy; and a battery of tests of absorption by the small gut, of which absorption of fat by the fat balance and ${ }^{131}$ iodinelabelled triolein techniques, of xylose and of radioactive iron are the most widely used. In practice, in the absence of diarrhœa, which occurs in about $95 \%$ of all cases of malabsorption syndrome (Bossak, Wang and Adlersberg, 1957) and in less than $10 \%$ of patients with pernicious anæmia (Davidson, 1957), the most useful single test is of acid production in response to an effective dose of a powerful stimulant of the gastric parietal cells. Whereas demonstrable acid secretion is absent or markedly impaired in pernicious anæmia (except in the rare juvenile type), in the malabsorption syndrome gastric secretion of acid is normal or moderately impaired and only rarely falls within the range found in pernicious anæmia.

From the point of view of research, a means of proper assessment of parietal cell activity in pernicious anæmia and in other diseases is still wanting. The essential problem is how to make correction for reabsorption by the stomach, for the passage of gastric contents into the duodenum during the period of the test and for neutralization by duodenal regurgitation and by secretions from non-parietal cell sources. To establish arbitrary 
limits of $\mathrm{pH}$ change and volume of juice produced, or merely to express the number of hydrogen ions apparently produced in unit time by titration to some preselected neutral point, only begs the question. Since mucus has little buffering action, measurement of milli-equivalents of hydrochloric acid, of chloride and volume of juice provide the best approximation to a proper measurement of parietal and non-parietal cell activity. However, complete recovery of gastric juice by aspiration is almost impossible, so that considerable error is likely to be present. Elaborate techniques, using dyes or radio-isotopes and measuring their dilution by the gastric content, have gone some way to overcome this problem, but have yet to be introduced into general clinical practice.

Direct measurements of $\mathrm{pH}$ on the surface of the gastric mucosa may have a place in assessing parietal cell activity (Kinzlmeier, Demling and Mannus, 1952), but at present the technique is crude and not very reliable and more development and calibration are needed.

Certain other tests which yield useful information must be mentioned.

Radiological examination of the stomach may support other evidence of gastric atrophy (Badenoch, Kemp and Richards, 1956), but is not of much value in establishing the diagnosis. It is important to emphasize that such an examination should be made in every patient with suspected pernicious anæmia, in view of the possible presence of gastric carcinoma. Many patients with untreated pernicious anæmia are too anæmic and mentally disturbed to co-operate really satisfactorily for a proper barium meal examination. This applies particularly to the aged. Such patients should not therefore be examined radiologically until they have begun to respond to therapy.

Studies of gastric exfoliative cytology may become increasingly valuable in detection of carcinoma, though there is the possibility of sheets of non-malignant cells, exhibiting certain features of vitamin $\mathrm{B}_{12}$ deficiency, being confused with malignant cells, even by workers skilled in the technique.

\section{Other Tests of Gastric Function}

The marked depression of pepsinogen secretion by the chief cells may be detected by demonstrating reduction of proteolytic activity at low $\mathrm{pH}$ in samples of gastric juice or, since part at least of the chief-cell secretion is released into the blood stream, by demonstrating reduction of similar activity in plasma or in the urine. Measurement of uropepsinogen excretion is one of the most valuable and simple screening tests of gastric function.

It is clear that the only lesion pathognomonic of pernicious anæmia is a failure of the gastric mucosa to secrete intrinsic factor. Tests of intrinsic-factor secretion, which can be used in centres other than those concerned particularly with research in pernicious anæmia, became available nearly ten years ago when cyanocobalamin labelled with radioactive cobalt was introduced (Heinle, Welch, Scharf, Meacham and Prusoff, 1952). The commonly used isotopes are ${ }^{57} \mathrm{Co}$, ${ }^{58} \mathrm{Co}$ and ${ }^{60} \mathrm{Co}$. Before that time, the Castle test, in which was measured the capacity of a sample of the patient's gastric juice incubated with a source of extrinsic factor, to induce a hæmatological remission in another patient with untreated pernicious anæmia, was the only means of detecting the presence of intrinsic factor. It is easy to understand the relatively slow progress in this field between 1930 and $195^{\circ}$.

Intrinsic factor may now be detected: in three ways: (I) The patient's capacity to absorb a 'physiological' dose of the labelled vitamin can be measured. (2) The patient's gastric juice can $\infty$ be given by mouth, with a dose of labelled 윽 vitamin $\mathrm{B}_{12}$, to another patient with pernicious anæmia. (3) The capacity of the patient's gastric juice to augment the uptake of vitamin $B_{12}$ by liver slices or homogenates may be tested (Miller $\stackrel{\text { क }}{\rightarrow}$ and Hunter, 1957). The second and third methodg $\vec{\theta}$ involve intubation of the patient. The secong o method is seldom applicable, because the volums. of gastric juice obtainable is often markedly reduced when gastric mucosal function is disturbed, and in the third test it has yet to be convincingly demonstrated that what is being tested is intrinsic factor. Attempts are being made to introduce a satisfactory animal preparation for the assay of human intrinsic factor, but it seems most likely that some initial purification of the gastric juice is necessary, since activity may be masked by speciesspecific inhibitory factors.

There are four different ways of performing the first test. The first is to measure the excretion of radioactivity in the fæces (Heinle, Welch, Scharf, Meacham and Prusoff, 1952). This is probably the most satisfactory test of all, but its weakness lies in the possibility of loss of some of the excreta. The second is the urinary excretion test devised by Schilling (1953). This takes 24 to 48 hours, instead of 6 to 8 days as in the $\mathcal{N}$ fæcal test. It has the disadvantage that it involves $N$ giving a large dose of vitamin $\mathrm{B}_{12}$ intramuscularly (the 'flushing' dose of $1,000 \mu \mathrm{g}$. given two hours after the small oral dose of 0.5 to $1.0 \mu \mathrm{g}$. of abelled vitamin $B_{12}$ ), which induces a rem ission and changes the concentration of vitamin $B_{12}$ in $\stackrel{\odot}{?}$ the serum, but for ordinary diagnostic work it is of great value. The third method is to assess radioactivity present in the liver after giving an 
oral dose of labelled vitamin (Glass, Boyd, Gellin and Stephanson, i954). This test requires the same time as the first, since it is important that unabsorbed vitamin in the colon should have been excreted and not interfere with surface counting over the liver. It is difficult to quantitate and its only advantage is that it provides a measurement related to absorption instead of excretion. Finally, measurements have 'been made of radioactivity in the plasma after an oral dose of the labelled vitamin (Doscherholmen and Hagen, 1957b); but the results of such tests are dependent both on absorption and turnover, and the count rates are extremely low if permissible limits of radioactivity are observed. This method is unlikely to be widely applied.

The most promising development may be of an efficient total body counter, but such apparatus is not yet generally available.

The absorption of vitamin $B_{12}$ may be impaired both in the absence of intrinsic factor and in small bowel disease. Thus a finding of impaired absorption should be followed by a test of absorption of the vitamin given together with a potent source of intrinsic factor, usually of pig or human origin. In pernicious anæmia there is restoration of normal absorption, whereas in the malabsorption syndrome the response is usually trivial unless the dose of intrinsic factor is large.

\section{Serum Vitamin $B_{12}$ Activity}

Measurements of the concentration of vitamin $B_{12}$ activity in serum involve microbiological assay using micro-organisms such as Lactobacillus leichmannii or Euglena gracilis. Such measurements are not essential for the diagnosis of pernicious anæmia, though a finding of a normal serum level excludes untreated pernicious anæmia as a cause of a megaloblastic blood picture. An abnormally low level does not exclude the small intestinal malabsorption syndromes, in which deficiency of vitamin $B_{12}$ and of folic acid may occur together. No really satisfactory test for folic acid deficiency has yet been devised:

Neurological lesions due to deficiency of vita$\min B_{12}$ may rarely occur without associated hæmatological changes. Estimation of the vitamin $B_{12}$ activity of the serum may be of value in differentiating between these cases and other neurological conditions such as disseminated sclerosis and neoplasms of the central nervous system. This is the most important application of such estimations in clinical practice.

\section{Treatment}

The proper treatment of pernicious anæmia is with vitamin $B_{12}$. The best argument for intramuscular therapy is that the patient is kept under surveillance and is not likely to relapse, through carelessness or forgetfulness, into a state of vitamin $B_{12}$ deficiency. Such a relapse may produce irreversible damage to the nervous system and is therefore potentially dangerous, in contrast to relapses in iron-deficiency anæmia caused by failure of the patient to maintain adequate medication.

The daily requirements of vitamin $\mathrm{B}_{12}$ are not known. Estimates range from I to $8 \mu \mathrm{g}$. per day in the adult (Gräsbeck, 1959). Doses of $100 \mu \mathrm{g}$. every three to four weeks may usually be adequate, but occasionally patients seem to require rather more, not because they run sub-optimal blood pictures on the usual dose, but because they feel stronger and have better appetites when given a larger dose. Such clinical impressions deserve a properly conducted trial.

Initial therapy with vitamin $B_{12}$ is best given in a dose of $100 \mu \mathrm{g}$. i.m. daily for ten days. The response is seen first in the patient's feeling of increased well-being, and mental improvement, often within 48 hours of the first injection. The reticulocyte response should occur within I 4 days and rise within two to three days to a peak, falling quite rapidly. The hæmoglobin response begins at about this time. Delay in reticulocyte response beyond 14 days demands reappraisal of the diagnosis, but, if the initial hæmoglobin concentration is above $10 \mathrm{~g}$./100 $\mathrm{ml}$., the reticulocyte response may be small and hæmoglobin rise is the best index of response to therapy.

An early sign of response of the marrow to vitamin $B_{12}$ is a rapid fall in concentration of serum iron, which is high in the untreated disease (Hawkins, 1955). Such a fall may occur within 24 hours of starting treatment.

Sometimes the rise in hæmoglobin concentration flattens out and the mean corpuscular hæmoglobin concentration falls; signs of iron deficiency may appear (Fig. 3). Rarely the patient develops koilonychia and angular stomatitis. In these patients iron should be given in adequate dosage. There is no evidence that such masked deficiency of iron is due to malabsorption of iron in pernicious anæmia, and if iron deficiency does become manifest in this way, possible causes are heavy menstruation or some site of bleeding in the gastrointestinal tract, which must be looked for.

That cyanocobalamin is the best preparation in the treatment of pernicious anæmia has been questioned. Some evidence suggests that hydroxocobalamin is more akin to the form in which the vitamin occurs naturally in the tissues, and also that intramuscular injections of hydroxocobalamin maintain more persistently high plasma concentrations with reduced excretion in the urine (Glass, Skeggs, Lee, Jones and Hardy, r961). 


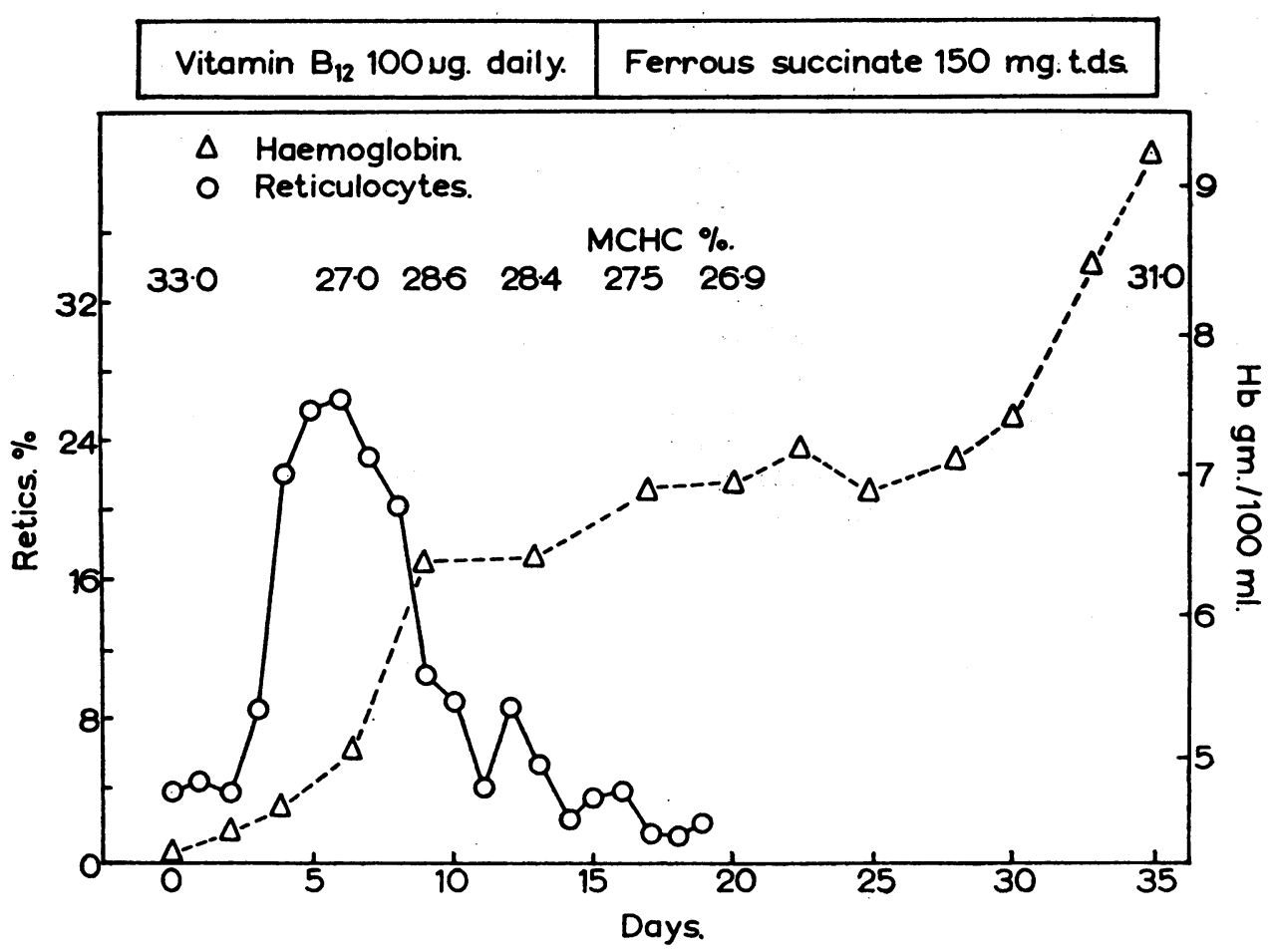

FIG. 3. - Unmasking of latent iron deficiency during response to vitamin $\mathbf{B}_{12}$.

From a practical point of view such a problem is not very important.

For those who wish to treat their patients orally, three types of preparation are available: First, there is cyanocobalamin alone, which in doses of $100 \mu \mathrm{g}$. daily is effective. Secondly, a complex of vitamin $\mathrm{B}_{12}$ and hog intrinsic factor may be used. . Those preparations containing partially purified intrinsic factor may induce in some patients a refractory state. Finally, vitamin $B_{12}$-polypeptide complexes have been marketed recently for which claims of preferential absorption have been made (Heathcote and Mooney, 1958). These have not been substantiated.

\section{Etiology of Pernicious Anæmia}

Recent reviews (Coghill, I960; Taylor, 196I) testify to our ignorance of the processes responsible for chronic gastritis and gastric atrophy. The causes of gastric atrophy and of deficient secretion of intrinsic factor are not necessarily the same. Only in juvenile pernicious anæmia is the separation of the two conditions obvious. In adults all that can be stated with confidence is that some patients with well-established atrophic gastritis have not lost the capacity to absorb vitamin $B_{12}$. Furthermore, when absorption of the vitamin is impaired and low concentrations appe in the blood, a megaloblastic anæmia does not invariably result. Faber (1935) advanced the view that gastritis was a progressive disease, ranging $\stackrel{\circ}{\varnothing}$ from superficial gastritis through atrophic gastritis to gastric atrophy. Evidence available today can neither refute nor confirm this view, nor throw much light on the causation of chronic gastritis. Studies with the gastroscope and by gastric biopsy have provided information about many factors which are capable of producing acute gastritis. Perhaps the most dramatic feature of such acute gastric lesions is their speed of healing (Palmer, 1954), which lends no support to the hypothesis that acute gastritis may lead on to the chronic disease. However, it is possible that in some subjects, possibly predisposed by hereditary or environmental factors, acute lesions may become chronic. The study of Edwards and $/ 0$ Edwards (1956) relating the heat of ingested fluids $N$ to the incidence of chronic gastritis, is of interest. There is a possibility that auto-immune processes may play a part in the development of pernicious anæmia in some cases (Taylor, I959, 196I) and that such processes may be responsible for perpetuating gastric damage.

Evidence of hereditary influences in pernicious anæmia comes from family studies (Callender 
and Denborough, 1957; McIntyre, Hahn, Conly and Glass, 1959), from studies of certain physical characteristics showing a significant predominance of blood group A and blue eyes (Callender, Denborough and Sneath, 1957) and from studies showing a higher incidence of gastric carcinoma in pernicious anæmia and the relatives of patients with pernicious anæmia (Mosbech and Videbaek, 1950; Mosbech, 1953).

Only one proper geographical survey of pernicious anæmia has been made and this has been confined to Great Britain (Scott, 1960). The reasons for quite marked regional differences are obscure, though nutrition may be important.
However, there is still no convincing evidence that dietary factors play a significant part in the ætiology of pernicious anæmia. Both alcoholism and iron deficiency have been much studied in relation to chronic gastritis and the results have been inconclusive. All available evidence suggests that a deficiency of vitamin $B_{12}$ is a result and not a cause of disease of the gastric mucosa.

Such ignorance must hinder any but the most empirical attempts to reverse or prevent the pathological changes in the stomach which we believe to be an essential part of pernicious anæmia in most patients, but should stimulate research in this fascinating field.

\section{REFERENCES}

Abels, J. (1959): Intrinsic Factor van Castle en Resorptie van Vitamine $B_{12}$, Thesis, University of Croningen.

Badenoch, J., Kemp, F. H., and RichaRds, W. C. D. (1956): The Radiological Diagnosis of Gastric Atrophy, Gastroenterologia (Basel), 85, 216.

Booth, C. C., Chanarin, I., Anderson, B. B., and Mollin, D. L. (1957): The Site of Absorption and Tissue Distribution of Orally Administered ${ }^{56} \mathrm{Co}$-labelled Vitamin $\mathrm{B}_{12}$ in the Rat, Brit. $\mathcal{Y}$. Hamat., 3, 253.

, and MolliN, D. L. (1959): The Site of Absorption of Vitamin $B_{12}$ in Man, Lancet, $i, 18$.

Bossak, E. T., Wang, C. I., and Adlersberg, D. (1957): Clinical Aspects of the Malabsorption Syndrome (Idiopathic Sprue), f. Mt Sinai Hosp., 24, 286.

Bromer, W. W., and Davisson, E. O. (1961): Biochem. Biophys. Research Commun., 4, 61.

Callender, S. T., and Denborough, M. A. (1957): A Family Study of Pernicious Anæmia, Brit. Y. Hamat., 3, 88. - - and SNEATH, J. (1957): Blood Groups and other Inherited Characters in Pernicious Anæmia, Ibid., 3, 107. Coghill, N. F. (I960): The Significance of Gastritis, Postgrad. med. $\mathcal{f}$., 36, 733 .

CoOPER, B. A., and CASTLE, W. B. (1960): Sequential Mechanisms in the Enhanced Absorption of Vitamin B 12 by Intrinsic Factor in the Rat, $\mathcal{F}$. clin. Invest., 39, 199.

Davidson, S. (1957): Clinical Picture of Pernicious Anæmia Prior to Introduction of Liver Therapy in 1926 and in Edinburgh Subsequent to 1944, Brit. med. $\mathcal{Y}$., i, 241.

Deller, D. J., Germar, H., and WiTts, L. J. (r96I): Effect of Food on Absorption of Radioactive Vitamin B ${ }_{12}$, Lancet, i, 574 .

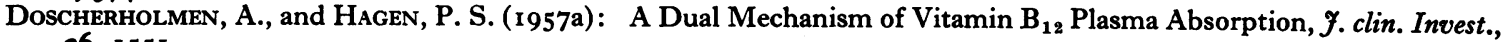
36, 155 I.

the Blood

EDWARDS, F. C., and EDWARDS, J. H. (1956): Tea-drinking and Gastritis, Lancet, ii, 543.

FABER, K. (1935): 'Gastritis and its Consequences'. London: Oxford University Press.

FenwiCK, S. (1870): On Atrophy of Stomach, Lancet, ii, 78.

Glass, G. B. J., Boyd, L. J., Gellin, G. A., and Stephanson, L. (1954): Uptake of Radioactive Vitamin B 12 by the Liver in Humans: Test for Measurement of Intestinal Absorption of Vitamin $B_{12}$ and Intrinsic Factor Activity, Arch. Biochem., 51, 251. 'Technic., Proc. Soc. exp. Biol. (N.Y.), 86, 522.

- Skeggs, H. R., Lee, D. H., Jones, E. L., and HARDy, W. W. (I96r): Applicability of Hydroxocobalamin as a Long-acting Vitamin $\mathrm{B}_{12}$, Nature, 189,138 .

GräsBeCK, R. (1959): Maintenance Treatment in Pernicious Anæmia, Lancet, i, 206.

Hawkins, C. F. (1955): Value of Serum Iron Levels in Assessing Effect of Hæmatinics in the Macrocytic Anæmias, Brit. med. $\mathcal{Y}$., i, 383 .

Heathcote, J. G., and Mooney, F. S. (1958): The Oral Treatment of Pernicious Anæmia, Lancet, i, 982.

Heatley, N. G., Sheikh, M. A., and TAYlor, K. B. (1960): Some Experiments on Intrinsic Factor, Biochem. $\mathcal{F}$., 76,342 .

Heinle, R. W., Welch, A. D., Scharf, V., Meacham, G. C., and Prusoff, W. H. (1952): Studies of Excretion (and Absorption) of ${ }^{\circ} \mathrm{Co}$-labelled Vitamin $\mathrm{B}_{12}$ in Pernicious Anæmia, Trans. Ass. Amer. Phys., 65, 214.

Johnson, B. C. (1955): Absorption and Utilization of Vitamin B12: Symposium on Nutritional Aspects of Blood Formation, Amer. Y. clin. Nutr., 3, 50.

Kinzlmeier, H., Demling, L., and Mannus, E. (1952): Uber die Sauretopik der Menschlichen Magenschleinhaut, Z. ges. inn. Med., 7, 516.

Lambert, H. P., Prankerd, T. A. J., and Smellie, J. M. (r96r): Pernicious Anæmia in Childhood, Quart. Y. Med.,

McINTYRe, P. A., HAHN, R., Conley, C. L., and Glass, B. (1959): Genetic Factors in Predisposition to Pernicious Anæmia, Bull. Yohns Hopk. Hosp., ro4, 309.

Miller, O. N., and HunTER, F. M. (1957): Stimulation of Vitamin $B_{12}$ Uptake in Tissue Slices by Intrinsic Factor Concentrate, Proc. Soc. exp. Biol. (N.Y.), 96, 39. 
Mosbech, J. (1953): 'Heredity in Pernicious Anæmia'. Copenhagen: Munksgaard.

- , and Videbaek, A. (1950): Mortality from and Risk of Gastric Carcinoma Among Patients with Pernicious Anæmia, Brit. med. F., ii, 390.

Palmer, E. D. (1954): Gastritis: A Revaluation, Medicine, 33, 199.

Reizenstein, P. G., and Nyberg, W. (1959): Intestinal Absorption of Liver-bound Radiovitamin B 12 in Patients with . Pernicious Anæmia and in Controls, Lancet, ii, 248.

Reynell, P. C., Spray, G. H., and Taylor, K. B. (1957): The Site of Absorption of Vitamin B12 in the Rat, Clin. Sci., 16, 66.

Ross, J. F., Belding, H., and Paegel, B. L. (1948): The Development and Progression of Subacute Combined Degeneration of the Spinal Cord in Patients with Pernicious Anæmia Treated with Synthetic Pteroyl-glutamic (Folic) Acid, Blood, 3, 68.

Ross, G. I. M., Mollin, D. L., Cox, E. J., and Ungley, C. C. (I 954): Hæmatologic Responses and Concentration of Vitamin $\mathbf{B}_{12}$ in Serum and Urine Following Oral Administration of Vitamin $\mathbf{B}_{12}$ Without Intrinsic Factor, Blood, 9, 473 .

Schilling, R. F. (1953): Intrinsic Factor Studies: II. The Effect of Gastric Juice on the Urinary Excretion of Radioactivity After the Oral Administration of Radioactive Vitamin $\mathrm{B}_{12}, \mathcal{F}$. Lab. clin. Med., 42, 860.

Schwartz, M., Lous, P., and Meulengracht, E. (1957): Reduced Effect of Heterologous Intrinsic Factor After Prolonged Oral Treatment in Pernicious Ánæmia, Lancet, i, $75 \mathrm{i}$.

Scott, E. (1960): Prevalence of Pernicious Anæmia in Great Britain, F. Coll. gen. Pract., 3, 80.

SlungaARD, R. K., and Higgins, G. M. (1956): Experimental Megaloblastic Anæmia in Young Guinea-pigs, Blood, II, 123.

Smiтh, E. L. (1958): Biochemical Functioning of Vitamin $\mathrm{B}_{12}$, Nature, $181,305$.

Spray, G. H. (1952): The Effect of Heat on the Microbiological and Anti-anæmic Properties of Human Gastric Juice Mixed with Vitamin $B_{12}$, Biochem. $\mathcal{Y}, 5^{50}, 587$.

Stadtman, E. R., Overath, P., Eggerer, H., and Lynen, F. (I960) : Role of Biotin and Vitamin B 12 Coenzyme in Propionate Metabolism; Biochem. Biophys. Res. Commun., 2, i.: New York: Academic Press.

TAYloR, K. B. (r959): An Antibody to Castle's Intrinsic Factor: Proceedings of VIIth International Congress of Hæmatology (Rome, 1958), Hamatol. Latina, 2, 181.

- (r96r): Chronic Atrophic Gastritis and Pernicious Anæmia, Gastroenterology (in press).

- and French, J. E. (1960): The Role of the Lymphatics in the Intestinal Absorption of Vitamin $B_{12}$ in the Rat, Quart. F. exp. Physiol., 45, 72.

-, MalletT, B., and SPRAY, G. H. (r958): Observations on the Inhibitory Effects of Intrinsic Factor Preparations on Vitamin $B_{12}$ Absorption, Clin. Sci., 17, 647.

- - - WITTS, L. J., and TAYLOR, W. H. (1958): Observations on Vitamin B $_{12}$ Absorption in the Rat, Brit. 7 Hamat., 4, 63.

Wasserman, L. R., Estren, S., Brody, E. A., and Herbert, V. (1960): Intestinal Absorption of Vitamin B ${ }_{12}$, Lance i, 173.

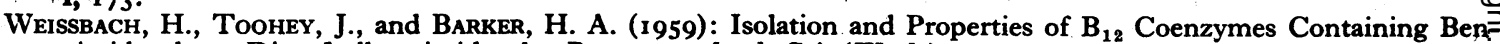
zimidazole or Dimethylbenzimidazole, Proc. nat. Acad. Sci. (Wash.), 45, 52 I. 